\title{
Performance Appraisals As Motivational Tools For Increased Productivity
}

Martin D. Carrigan, JD, The University of Findlay, USA

\begin{abstract}
Organizations, as part of their own competitive strategy, need motivated employees producing at the highest level to outsell their competition and become industry leaders. Performance Appraisals can accomplish this goal.
\end{abstract}

\section{OVERVIEW OF THE THEORIES OF MOTIVATION}

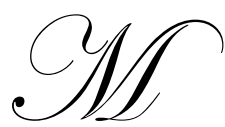

otivation is the force, internal or external, that creates enthusiasm and persistence to pursue a certain course of action. (Daft, 2005, p. 294). One of the key functions of manager is to motivate employees to increase their individual and organizational production and performance. At the same time, properly designed performance appraisal tools can satisfy employee needs. A highly motivated employee may also be a top performer within an organization. Because there are many ways to motivate people, however, managers must learn to adapt their approach to the individual.

\section{A. Herzberg}

According to behavioral scientist, Frederick Herzberg, "the best way to motivate the work force is to create opportunities for challenge and achievement into their jobs through job" (Dessler, 2005, p. 138). Job enrichment is achieved by adding motivators to it to make it more rewarding and encourages a desire for self-improvement. Generally, it means making a job more humanized by addressing both basic needs and higher level needs of employees. To increase the chances that employee's find their work intrinsically rewarding, organizations can enrich their jobs by giving them the opportunity to acquire a new skills or demonstrate a new competency. Affording employees the chance to manage a project from start to finish and at the end of the project be able to show the successful results they have achieved gives them a sense of pride in their work. Also allowing employees to work on a project that has a high impact on the organization provides intrinsic rewards. In attempting to enrich jobs, organizations must be careful not to simply add routine job duties to an employee's current responsibilities, add to the level of productivity expected just because they meet current expectations, and don't use job rotation to move someone into a job that does not provide some kind of challenge (Deeprose, 2007, p.94).

Herzberg developed his two factor model in the 1950's. He argued that motivation is divided into two factors. Hygiene factors are elements such as pay, status, job security, benefits, working conditions, and policies and practices. Provided by managers or individuals higher up in the organization, Herzberg contended these external or extrinsic factors might improve short-term job satisfaction but they do not necessarily motivate. If hygiene factors are inadequate, almost certainly, employees have low job satisfaction. Regardless of whether managers have the ability to change hygiene issues concerning employees, they should be acknowledged. Empathy toward others goes a long way in understanding what motivates employees.

The other factor Herzberg suggested, called motivators, are within the employee's control. He proposed hygiene factors alone are only a part of motivation and believed creating a motivated workforce depended more on intrinsic rewards. Internal factors such as the fulfillment one receives from completing a challenging assignment, achievement, meaningfulness, and a sense of accomplishment are some examples of what he believed truly motivated people long term. 


\section{B. Maslow}

Scientist Abraham Maslow offered a needs-based theory of motivation which says lower level needs must be met before the higher level needs will motivate another behavior in employees. Maslow's five levels of need included physiological needs, safety needs, belonging needs, esteem needs and self actualization needs. He believed the first three needs were lower level and must be met before the employee would be concerned with the higher level needs. For example, if a person does not have food or water, they will focus their attention on those basic life sustaining necessities before they will be able to concern themselves with esteem needs such as their recognition from their supervisor. "Essentially, employees are more enthusiastically motivated by what they are seeking than by what they already have, but they move forward with enthusiasm only when they are seeking something else" (Davis \& Newstrom, 1989, p. 109).

\section{McClelland}

David McClelland, who studied motivational theories for over twenty years, developed the acquired needs theory, emphasizing the belief that some needs are acquired during one's lifetime, specifically the need for achievement, affiliation, and power. His research showed that people's motivational drives reflect elements of the culture in which they grew up, like family/friends, school, church and media (Davis \& Newstrom, 1989, p. 103). Achievement addresses one's need to attain success or a higher level of success than others. The need for affiliation means the desire to develop personal relationships, to bring together people and different groups within an organization. Finally, the need for power often describes someone who seeks to move upward and make an impact on an organization throughout their career.

The theories discussed above identify specific needs that motivate people. If managers can identify the needs of their employees and successfully meet them, employees will very likely demonstrate desired behaviors in the work place bringing about increased productivity and profit.

\section{OVERVIEW OF EXTRINSIC AND INTRINSIC REWARDS}

\section{A. Money}

The list of rewards and recognition used to motivate workers is long and many have argued the effectiveness of each method. Money is often the first type of reward that comes to mind when thinking about motivation. But can money really motivate a person to perform at their peak? Deeprose (2007) suggests it "depends on how money is used as to whether it can motivate. Most would agree salaries are not motivators; they are an employee's expectation for doing their job. Furthermore, not receiving a raise or getting a raise lower than what was expected, has a negative effect on a person's level of motivation" (p. 20).

When employees are eligible to receive a financial reward for meeting established criteria, they are more likely to perform at a higher level than those that are not. The key is to provide them with clear, specific information and review it periodically so they understand their progress in reaching the goal. Spot bonuses can also be used as a way to show appreciation for an employee's exceptional performance. "These bonuses do not have to be big but should be presented for specific behaviors or achievements, immediately following the noteworthy performance" (Deeprose, 2007, p. 21). There is less of an impact if the reward is given too far from the time of the behavior.

That being said, money as a long term motivator has its proponents and detractors. According to social critic Alfie Kohn (cited in Kriegel and Brandt, 1996), "while rewards are effective at producing temporary compliance, they are strikingly ineffective at producing lasting change in attitudes or behavior" (p. 261). As introduced by Frederick Herzberg, people are more motivated by intrinsic factors such as meaningful work, flexibility, recognition for a job well done, and belonging and acceptance. They are less motivated by extrinsic factors like money and material things. According to Herzberg, "compensation will, at best, prevent employees from being dissatisfied with their environment. Recognition, however, motivates" (cited in Jensen \& McMillen \& Stark, 2007, p. 215). 


\section{B. Is money a demotivator?}

For example, rewards are not always positive motivators but sometimes actually become demotivators. When a worker is recognized for a particular contribution, they see themselves as recognized. Herrera (2002) proposes "if the level of recognition is not at least equal to the person's perception of the effort they exerted toward the action, the reward becomes a negative motivator" (p. 44).

\section{Employee development}

Employee development, an intrinsic motivator, gives employees an opportunity to grow both personally and professionally. Employee development also benefits the company who gains an even more educated and prepare workforce. Hopkins (1995) offers five categories of development activities that will assist managers in effectively motivating employees and increasing their morale.

1. Social gatherings such as company picnics, family days, or philanthropic work gives employees a sense of belonging and through this, employees will take ownership of their jobs which leads to higher morals.

2. Recognizing employee contributions, no matter how small, is an important motivator. Also, nothing is more motivating than to recognize someone's accomplishments in front of the entire company. It helps motivate others to strive to achieve similar results so they too can be rewarded for their efforts.

3. Providing opportunities for employees to continue their education improve both their knowledge base and their work performance. Employees become more self-confident and in essence become more motivated about their work and responsibilities.

4. Employee meetings show support for employee's ideas and concerns as they relate to the company's needs. They are a good way to promote upward communication within the company.

5. Though not a specific activity, empowerment increases motivation. It is important to allow employees to participate in the decision making process (p.26-27).

\section{Empowerment}

Another approach used to motivate employees is empowerment. "The need for empowerment is a direct consequence of the attempts by organizations, through de-layering and right-sizing, to increase efficiency, effectiveness and meet the needs of increased competition" (Smith, 1997, p. 120). Empowerment, which satisfies intrinsic needs, is a concept or a way of distributing power down to lower levels of the organization. It can be difficult to implement because it means less power and more trust from top management. It also refocuses efforts away from traditional extrinsic reward programs and emphasizes intrinsic satisfaction employees get from doing a job well. Empowerment allows employees to flourish and find meaning in their jobs. It also brings the organization different ideas and new approaches to problem solving from a larger, more diverse group of people.

To expand on the concept of empowerment, Independent Consultant and Editor Bryan Smith (1997) suggests that "by giving employees more control over how to do their job, comes immense potential for improving productivity. Empowerment supports and promotes learning from experiences and personal growth" (p. 120). Often, additional responsibility, decision making power and autonomy bring increased motivation and a decrease in employee absenteeism and turnover. It allows employees to satisfy intrinsic needs through their work.

Daft (2000) suggests there are several factors that must be present in order for empowerment to be effective. (1) Information about company performance must be shared with the employees. (2) Companies must provide employees with the training and knowledge necessary to contribute to the company's goals. (3) Employees are able to influence company direction and make substantive decisions through self-directed work teams. (4) Employees understand the impact their work has on all parties involved and consider what they do to be important. (5) Company performance determines how employees are rewarded. Many times this means profit sharing and employee stock ownership (p. 317-318).

There are a considerable number of benefits that come from empowering people to use their expertise and skills to get their jobs done without constant direction from management. Being given the freedom to use their 
creativity to problem solve or draw on their knowledge to complete a complex task satisfies an individual's need for self-efficacy. From a higher level, some leaders believe giving up some control will encourage speed, flexibility and decisiveness in the workforce, leading to a smooth running, efficient organization.

\section{E. Inspiration \& Recognition}

Creating meaning within an organization gets people excited about their work and inspires them to perform at a high level. When employees can relate to the organization's identity, it gives them a sense of belonging purpose in their work. Without inspiration, workers lack the drive necessary for top performance. Stallard (2007) suggests there are several ways managers can help employees find meaning in their work, regardless of the product or service they are producing. Demonstrate how the product brings something innovative and new to the industry. Challenge employees to reach a stretch goal or be the best in the industry. This brings about good competition and motivates. It is especially effective if data from competitors is available for comparison. Get employees connected to the organization right from the start. New hire orientation is a great place to convey the organization's mission and culture and help them understand their role in it. Find ways to continuously share the vision and identity. It is important to gain employee commitment and maintain an organization where people work together to achieve common goals. Finally, in addition to verbal communication, managers can use written communication as a tool to encourage people and influence behavior (p. 51-56). Regardless of the approach, providing meaning and inspiring people in the workplace is critical to the success and longevity of any organization.

Some argue, recognition above all else, is the most powerful and effective tool used to motivate employees. One key point regarding recognition programs is that they can be much less costly than traditional monetary reward programs and can be more effective too. Organizations have found that behaviors and efforts that get recognized get repeated. Different from performance management, which will be discussed later, recognition programs acknowledge specific behavior and not sustained peak performance. "Recognition is not a replacement for performance management, but rather a process for improving performance through people. Recognizing events, activities, and efforts after the fact may not drive improved performance, but it will reinforce it" (Jenson \& McMullen \& Stark 2007, p. 217).

There are several elements that make up effective recognition programs to celebrate successes. People love seeing others being recognized for achieving a goal, accomplishing a daunting task, or for providing great customer service in a flashy awards event or ceremony. So it makes sense that recognition, and lots of it, should involve many employees. It not only motivates those receiving the recognition, but those applauding the recipient.

According to Levesque (2008), employee motivation and customer satisfaction are always mirror-images of each other. He suggests "where employees are cynical and demoralized, no amount of customer service training, no amount of disciplinary action, no amount of managerial pressure is going to get them consistently delivering a delightful customer experience". On the other hand, when employees are enthusiastic about doing their jobs, customer satisfaction is almost always a given (p. 130). In his book, Levesque also declares positive customer feedback is one of the most powerful employee motivators of all. If this is true, acknowledgement based on this feedback is a critical element of the recognition process.

Just as continuous recognition and celebration is important, the quality aspect is another factor to consider. There are four attributes of motivational celebration. First is the effort quotient. The amount of effort put forth to recognize someone for a job well done determines the level of effectiveness. "It tends to be directly proportional to the motivational effect the recognition will have on the recipient" (Levesque, 2008, p. 135). High effort recognition and one that has meaning increases the level of impact on the employee.

The second attribute is the internal/external meld. Levesque (2008) describes these recognition events as internally funded, externally triggered which enhances cultural alignment (p. 139). So even though the event is hosted management, it is in celebration of customer feedback. The key to these events is that the effort factor must also be present. 
Called the hero story, the third attribute focuses on stories of employee's specific action to help one or more specific customers in a profound way. Often they tell of employees helping customers in an unprompted, unplanned manner. Usually they are stories customers tell management after the fact, delaying the motivational effect until the internal recognition takes place. These stories are then celebrated in big, elaborate fashion. "When a business empowers its workers to look like heroes in customers' eyes, the mere loyal return of these customers becomes a motivational form of recognition and validation in and of itself' (Levesque, 2008, p. 142).

The last attribute of motivational celebration is a large audience. The level of motivational impact a celebration has on a person is determined, in part, by the number of people participating in the festivities. Clearly, an audience of five people applauding has less of an impact than an audience of 200. Another positive outcome of this type of celebration is that it creates a connection among the audience participants, giving them a sense of unity. Motivational celebrations, according to Levesque (2008) "awaken the spirit of volunteerism that may be lying dormant within many employees-their basic human need to fell useful and necessary in the world" (p. 147). They also drive other employees to provide the same type of remarkable customer service within their own jobs so they too can be recognized.

\section{A LEADER'S ROLE IN MOTIVATION}

Providing the right environment for employees to perform and be successful is an important function of any leader. "True motivation lifts the level of performance and produces a more valuable, committed employee" (Stettner, 2000, p. 70). Trusting employees, providing them with the right tools, and giving them freedom to get the job done are powerful motivators that contribute to their success and that of a manager. But before a manager can respond to the needs of his staff, he must develop trusting, mutually beneficial relationships.

Establishing these relationships are key to building rapport among employees. It encourages collaboration and team work and without it, employees will lack the motivation to reach their highest potential. Showing genuine interest in one's employees also demonstrates a leader's concern and empathy for their well being. In turn, subordinates will be more dedicated and willing to go the extra mile for their supervisor. "Without rapport, managers will get the minimum required from their people, but never anything more, and they will never take the team to new, important heights" (Snair, 2007, p. 143).

Well-informed employees are good and productive employees. Open, honest communication and sharing of information is another element in facilitating employee motivation and creativity. "Communication is the transfer of information and understanding from one person to another person. Without communication, employees cannot know what their coworkers are doing, management cannot receive information inputs, and supervisors cannot give instructions. Coordination of work is impossible, and the organization will collapse for the lack of it" (Davis \& Newstrom, 1989, p. 70-71).

According to Stallard (2007), "knowledge flow communicates people with less power in an organization that they appreciated and respected enough to be informed and heard and that their ideas can make a difference. It energizes and engages them" (p. 83). Another benefit of knowledge flow is an organization's ability to leverage ideas and experience from anywhere in the organization in order to make better decisions. Increased creativity and innovation is another positive outcome of knowledge flow. "When knowledge flows up and down and across the organization, it empowers people and makes them more effective in their jobs" (Stallard, 2007, p. 92). These are just a few of the clear benefits to keeping the lines of communication open and letting employee's know management values their input.

Conversely, communication can create unwanted difficulties and barriers among people. It can highlight differences of opinion between employees or work groups. This can create an unwanted barrier that can hinder creativity or productivity. Another negative outcome that can arise is cognitive dissonance. Defined as "an internal conflict and anxiety that occurs when people receive information incompatible with their value systems, prior decisions, or other information they may have", it makes people uncomfortable and want to reduce or eliminate it all together. Consequently, one must proceed with caution because communication reveals something about the sender while at the same time, judges others (Davis \& Newstrom, 1989, p. 75). 
Effective leaders understand the importance and benefits of delegating work. Whether it is delegating daily tasks or the management of a major project within the organization, it demonstrates a leader's trust in their employees and establishes creditability within the team. Entrusting employees shows you have the confidence in them to get the job done. It also builds trust among team members.

Once a leader has established these important relationships, it is their responsibility to identify what motivates his or her staff and then work to provide them with opportunities to be successful. "Leaders are responsible for going beyond removing dissatisfiers to using motivators to meet higher-level needs and propel employees toward greater achievement and satisfaction" (Daft, 2005, p. 300). Since Herzberg didn't believe hygiene factors were motivators, addressing factors such as achievement, responsibility, and meaningfulness becomes important.

In order to satisfy these needs, Ellis (2005) offers five motivators that leaders can institute within their organization.

1. Monitor and provide ongoing feedback regarding goal achievement.

2. Provide proper training taking into account the learning curve.

3. Give staff opportunities to manage and direct an activity.

4. Offer staff the chance to cross-train in other departments.

5. Provide training and learning opportunities on a subject staff wants to learn more about (p.89-90).

While the above suggestions by Ellis focus primarily on training and development, Stettner (2000) argues "most people are motivated by six needs: attainment, power, belonging, independence, respect, and equity". Again, these intrinsic needs, as Herzberg argued, were much more effective in motivating employees than financial rewards.

Employees that are motivated by challenging work and enjoy diving into a project to achieve success are motivated by attainment. These people want to develop their skills sets in order to advance within the company. Being the center of attention is a characteristic of people that are motivated by power. They strive for positions of leadership and the opportunity to influence others. Those who value social events and become engaged through their relationships with their co-workers are motivated by a sense of belonging. Team meetings also satisfy their need for belonging. Being given the freedom to work independently and the flexibility to problem solve the way they choose motivates those that are motivated by independence. The biggest demotivator for these people would be working on a project and being told exactly how to complete it and strict timelines for them to follow. These employees want the autonomy to establish their own set of rules. Some employees want to be heard and given full attention by their leaders. They want to be appreciated and given feedback on their performance. They are motivated by respect. While the goal of most leaders is to be fair to all their employees across the board, this becomes more important for employees that are motivated by equality. Leaders must make this a top priority and engage this group of employees by going out of their way to demonstrate they are indeed unbiased to any particular employees (p. 74).

Setting challenging goals encourages employees put forth extra effort resulting in higher performance. The key to encouraging peak performance from everyone, including top performers, average employees and even those that managers seem unable to motivate, is that the approach should be different. Deeprose (2007) recommends presenting top performers with these challenges to increase the level of motivation:

1. Allow employees to choose their own projects.

2. Give them the time and resources to work on projects they create and do not relate to their usual jobs.

3. Make these employees project managers, heading up cross functional teams, where promotional opportunities are few.

4. Provide them with opportunities to learn new skills, both in and outside of work and ensure they use the new skills at work.

5. Arrange for them to attend conferences or meetings normally reserved for top ranking personnel. 
For the group of employees that produces satisfactory work but falls short of turning out exceptional results, leaders should work with them to create goals that push them but are still achievable. No matter the type of employee a leader is trying to motivate the goal is the same; to reinforce the behavior so it will be repeated in all aspects of the employee's day-to-day responsibilities (p. 24-28.)

Poor performers and employees that nothing seems to raise their level of motivation require yet another approach. They fail to respond to promises of advancement, more money and more responsibility. Stettner (2000) advises managers to work with these employees individually to modify their job duties to include more challenging projects that focus on their areas of expertise. Allowing them the time to teach and train others in these areas can encourage them to become more engaged and interested in their work (p. 82,84). Deeprose (2007) offers a different method to engaging this group of individuals. She suggests rewarding a behavior instead of waiting to reward an outcome. If a particular behavior is not rewarded, the employee may not sustain it long enough to improve their performance (p. 63). Bottom line, reward even the smallest win for this group and eventually they will add up to something to rejoice over.

\section{INCREASING PRODUCTIVITY THROUGH PERFORMANCE MANAGEMENT}

Performance goals and measures provide employees with direction and expectations which motivate them to work toward achieving those outcomes. It is management's responsibility to set effective goals that inspire peak performance from their employees. Employee goals should be focused on helping achieve the company's strategic goals. Goals must be clear and identify what is important to the company. It gives employees the opportunity to contribute its success.

It is worth noting the distinction between performance appraisals and performance management. An appraisal is assessing one's performance against specific performance standards. Performance management combines goal setting, training, the appraisal, and rewards into a total package. It means having ongoing interaction with employees to review goal progress, ensure continuous performance improvement and providing training as necessary for the employee to carry out his or her job responsibilities successfully. A total performance management system also helps an organization's attempts at continuous improvement.

Involving employees in establishing goals can encourage their commitment to them. Jensen, McMullen, and Stark (2007) argue that "whether employees participate in the goal setting process, they should always be involved in discussions as to why the goals are important and why meeting deadlines is critical" (p. 47). Employee goal attainment depends on their understanding of exactly what the goals are, how they will be measured and what the rewards are if they meet them. In the end, a high level of employee performance results in happy, satisfied customers which increases company profits and growth over a period of time.

Because effective goal setting is so essential in determining whether an employee is able to achieve them, it is important to review the process. Goals should help employees focus their actions and help them to create strategies to achieve the set goals. Giving employees specific goals often results in a higher level of performance than those who are not. Leaders must ensure goals are attainable in order for them to have a positive influence on the employee's performance. If an employee feels they are unreasonable, it can actually have a negative effect on performance. The effectiveness of goals also depends on their ability to be measured. This can be done either by using quantitative terms or even providing achievable milestones throughout the project. Providing deadlines also clarifies and leaves less room for confusion among employees.

Appraising employee performance is important for several reasons. "Performance appraisal is a fundamental requirement for improving the productivity of an organization's human resources because it is through an appraisal that each individual's productivity is evaluated." (Latham \& Wexley, 1994, p. 6). Appraisals aid in development of employees which will encourage continuous improvement. It does little good to set employee goals based on those of the organization and provide training if periodic review of the performance is not a part of the process. The appraisal provides an opportunity for the supervisor and the employee to take action to correct any deficiencies identified in the appraisal. It allows time to review the employee's career goals based on his or her strengths and weaknesses. Organizations don't have control over the rising costs of materials and energy in today's 
poor economy, but they can control employee performance and productivity, and must. Finally, the performance appraisal is most likely to directly affect an employer's decision regarding promotional opportunities and salary raises for employees (Dessler, 2005, p. 313).

Providing employees with regular feedback gives them a sense of where they stand and suggestions for areas of development that will help them reach the desired outcomes. Deeprose (2007) proposes "managers need to keep up with employees' progress toward goals, facilitate employees' access to resources and guide them toward solutions to problems that block their progress" (p. 43). The performance appraisal is one tool used to facilitate this feedback. "Performance appraisals are crucial to the effective management of an organization's human resources, and the proper management of human resources is a critical variable affecting an employee's productivity" (Latham \& Wexley, 1994, p. 2).

Many organizations have implemented an appraisal system that includes feedback from a variety of sources, not just that of the immediate supervisor. This might include one's peers, subordinates, and even a selfappraisal. To be qualified to assess one's performance, Lathan \& Wexley (1994) argue that an individual "must be aware of the aims and objectives of the person's job, frequently observe the employee on the job, and be capable of determining whether the observed behavior is satisfactory" (p. 111). Peer appraisals, for example, are highly reliable and valid. This is because peers observe each other interacting with one another, with subordinates and managers. They have a wide-ranging view of their performance.

Appraisals given by subordinates are used most infrequently. It is thought these appraisals could weaken managerial power. There are however, benefits to conducting subordinate appraisals. Bernardin and Beatty (cited in Latham \& Wexley, 1994) suggested subordinates have a different vantage point regarding managerial performance than managers. They also help eliminate one-rater-only biases. Surprisingly, they also found that most managers said the feedback would be extremely valuable to them (p.120). Nevertheless, there are problems that can arise from this type of appraisal. Some subordinates may find this process intimidating because their supervisor may punish them for their honest, sometimes negative, feedback.

Many studies have been conducted to assess the validity of self-assessments. Though some of the outcomes have differed, many have actually found a high correlation between self-appraisals and that of the manager's assessments. In any case, most would agree there are both advantages and disadvantages to selfappraisals. One positive is the potential to increase self-motivation and ultimately, productivity. It can also improve one's self-respect and improve their understanding of the need for goals. On the other hand, a problem with this form of appraisal as noted by Harris \& Schaubroeck (cited in Latham \& Wexley, 1994) "is their lack of agreement with other sources of appraisal, especially supervisors". This is prevalent in jobs that are poorly defined. The key is to remove the aspects of the job that are unclear, so the evaluation criterion is obvious (p. 126).

Performance appraisals should used to measure performance against established measures and reward the individual accordingly. Latham \& Wexley (1994) believe "that the use of multiple sources of appraisal increases the probability of obtaining a comprehensive picture of an employee's total contribution to the organization" (p.136). Finally, performance management is one of the best tools available to organizations in which to measure performance and set a plan to increase performance and productivity of the long term.

\section{RETURN ON INVESTMENT}

Employee motivation, high organizational performance and profits all go together. A survey completed by the Gallup organization found that when all of an organization's employees are highly motivated and performing at their peak, customers are 70 percent more loyal, turnover drops by 70 percent and profits go up by 70 percent (cited in Daft, 2005).

If this is true, then why don't most organizations measure their return on investments? The answer is different for any organization but there may be factors some have in common. According to Jensen \& McMillen \& Stark (2007) measuring ROI may be up to finance or operations and not the compensation function of human resources. It may be too costly and difficult if financial and HR measurement and reporting systems are not in 
place. Another possible reason is that departments within HR operate as separate functional entities which can hinder communication between departments. Thus, each of these functional areas tend to focus only on the costs and returns for their particular areas. Additionally, $\mathrm{HR}$ as a whole has historically focused their efforts on measuring and monitoring the investments in compensation programs instead of their returns (p. 13).

An organization's compensation programs, investments, should not only include to monetary rewards. When workers are choosing which employers to work for or deciding to stay with a particular employer, it is often the intangible rewards that play a significant role in their decision. Indeed, they are a major factor in an organization's ability to recruit, retain and motivate employees. For example, training and development, intrinsic motivators, are highly valued among today's workforce. People understand their future employability depends on their ongoing efforts to improve their skills. Another factor important to employees is the understanding of the company's direction and trust in top management. They want to know where are headed to ensure their skills will continue to benefit the organization long term.

From a management perspective, the good news is that supervisors have the greatest control over the intangible benefits like working conditions and development opportunities. According to author Jac Fitz-enz (cited in Jensen \& McMillen \& Stark, 2007), the "principle driver of human performance and retention was the immediate supervisor or manager." He suggested seven items employees valued on the job.

1. Receive job-related training.

2. Receive career-development support.

3. Have advancement opportunity.

4. Be treated as a contributing adult.

5. Have personal knowledge and experience put to use.

6. Be kept informed about company matters and changes.

7. Be compensated fairly and equitably (p.19-20).

Noticeably, compensation is the lowest in order of importance. This reinforces the idea that monetary rewards are of lower value than intrinsic rewards and therefore should not be considered a primary factor in employee reward programs. That being said, a manager's ability to make a connection between rewards and performance proves critical to improving employee performance and therefore, contributions to the organization. The message is that to be able to effectively leverage them to increase motivation and ultimately ROI, managers must have a complete understanding of their value and how they relate to the overall business results.

As stated by Jensen \& McMillen \& Stark (2007), an example of an investment used to improve performance that is easy to quantify is measuring the costs training. The direct costs are the costs of developing and delivering training and the pay for employees while attending the training. In order for the training to have an ROI, employee performance must be higher after the training than before. There needs to be a clear increase in productivity, quality or some other performance metrics following training (p.21).

Regardless of whether organizations make the effort to actually calculate ROI they can benefit from identifying and implementing a reward system, made up of both intrinsic and extrinsic rewards that will likely produce the desired outcomes. "Managers who use all of the rewards elements available to them and who clearly link rewards to performance, ensure that they get an appropriate ROI from their people" Jensen \& McMillen \& Stark, 2007, P.28).

\section{CONCLUSION}

Winning organizations understand the significance of motivating employees and maintaining that motivation over the life of the business. Motivation effects productivity, employee morale, customer satisfaction, and profits, to name just a few. Its success depends on their ability to identify and meet the needs of their employees. It is important for managers to build trusting relationships that facilitate open communication and cooperation within departments and up and down the organizational chart. 
The majority of the literature concluded financial rewards can be effective in demonstrating appreciation but falls short as a lasting motivator. Intrinsic rewards have, however, been determined to be most satisfying and motivating over the long term. Intrinsic motivators such as development, empowerment, organizational identity and meaning, recognition, and performance management were all discussed in order to illustrate the variety of tools organizations can implement for the purpose of increasing motivation.

\section{AUTHOR INFORMATION}

Martin Carrigan is an Associate Professor of Law and Business at the University of Findlay, and the Director of Business Administration. He received his BA degree from the University of Notre Dame, his MBA from the University of Findlay, and his JD from the University of Toledo.

\section{REFERENCES}

1. $\quad$ Argyris, C. (May-June 1998): Empowerment: the emperor's new clothes. Harvard Business Review 76.n3 98(8).

2. Bethke, W. (2007). The Secret to an Effective Bonus Program. Review of Ophthalmology, 14(12), 28-30.

3. Brown, D. (1992, June). Why participatory management won't work here. Management Review, 42-46.

4. Byham, W. and Cox, J. (1989). Zapp! The lightning of empowerment. Pittsburgh, PA: Development Dimensions International Press.

5. $\quad$ Daft, R. L. (2005). The leadership experience. Mason, OH: South-Western.

6. Davis, K., \& Newstrom, J. (1989). Human behavior at work. New York: McGraw-Hill.

7. Deeprose, Donna (2007). How to recognize and reward employees. New York: American Management Association.

8. Dolan, T. G. (2008). Employee Incentives: A Delicate Balance. PT: Magazine of Physical Therapy, 16(1), 26-79.

9. Donovan, K. (2008). Instant reward licked. Employee Benefits, 39-40.

10. Ellis, C. W. (2005). Management skills for new managers. New York: American Management Association.

11. Emmerich, R (1997). Thank God it's Monday. Minneapolis MN: Banner Press

12. Glanz, B. (1996). Care packages for the workplace. United States: McGraw-Hill.

13. Gostick, A. and Elton, C. (2007). The carrot principle. New York, NY: Free Press.

14. Grant, A. M. (2008). Does Intrinsic Motivation Fuel The Prosocial Fire? Motivation Synergy in Predicting Persistence, Performance and Productivity. Journal of Applied Psychology, 93(1), 48-58.

15. Harris, J. and Brannick, J. (1999). Finding and keeping great employees. New York, NY: AMA

16. Harvey, E. 180 ways to walk the recognition talk. Dallas, TX: Performance Systems Corporation.

17. Herrera, F. (2002). Demystifying employee motivation. Employment Relations Today, 28(4), 37-52.

18. Hopkins, H. (1995). A challenge to managers: five ways to improve employee morale. Executive Development, 8(7), 26-28.

19. Huff, C. (2007, September 24). Motivating the World. Workforce Management, 25-31.

20. Imberman, W. (2008). Can You Motivate Your Workers? Official Board Markets, 84(1), 6-8.

21. Jaakkola, T., Liukkonen, J., Laakso, T., \& Ommundsen, Y. (2008). The relationship between situational and contextual self-determination motivation and physical activity intensity as measured by heart rates during ninth grade students' physical education classes. European Physical Education Review, 14(1), 1331.

22. Jensen, D., \& McMillen, T., \& Stark, M. (2007). The manager's guide to rewards. New York: American Management Association.

23. Ketter, P. (2008). What's the Big Deal: About Employee Engagement. $T+D, 62(1), 44-49$.

24. Kriegel, R., \& Brandt, D. (1996). Sacred cows make the best burgers. New York: Warner Books.

25. Latham, G. P., \& Wexley, K. N. (1994) Increasing productivity through performance appraisal. Reading, MA: Addison-Wesley Publishing Company.

26. Levesque, P. (2008). Motivation: powerful motivators that will turbo-charge your workforce. Madison, WI: Entrepreneur Media.

27. Lloyd, K. (2007). 151 quick ideas to recognize and reward employees. Franklin Lakes, NJ: Career Press 
28. Madlock, P. (Jan 2008) The link between leadership style, communicator competence, and employee satisfaction. The Journal of Business Communication 45.1 : 61(18).

29. Marston, C. (2005). Motivating the "what's in it for me?" workforce. United States.

30. Paradise, A. (2008). Influences Engagement. $T+D, 62(1), 54-59$.

31. Patterson, K., Grenny, J., Maxfield, D., McMillan, R., \& Switzler, A. (2008). Influencer: The power to change anything 1(). New York: McGraw-Hill.

32. Silverman, L. L. (2006). How Do You Keep the Right People on the Bus? Try Stories. Journal of Quality \& Participation, 29(4), 11-15.

33. Skemp-Arlt, K. M., \& Toupence, R. (2007). The Administrator's Role in Employee Motivation. Coach \& Athletic Director, 76(7), 28-34.

34. Smith, B. (1997). Empowerment - the challenge is now. Empowerment in Organizations, 5(3), 120-122.

35. Snair, S. (2007). The complete idiot's guide to motivational leadership. New York: Penguin Group.

36. Stallard, M. L. (2007). Fired up or burned out. Nashville, TN: Thomas Nelson.

37. Stettner, M. (2000). Skills for new managers. New York: McGraw-Hill.

38. Wildermuth, C., \& Wildermuth, M. (2008). 10M's of Employee Engagement. T+D, 62(1), 50-53.

39. Yerkes, L. (2001). Fun works. San Francisco, CA: Berrett-Koehler Publishers, Inc. 
Journal of Business \& Economics Research-August, 2009

Volume 7, Number 8

\section{NOTES}

